\title{
The Leisurely Nostalgic Feelings under the Traditional Culture Vision Based on the Appreciation of Hometown Banyan Tree
}

\author{
Yu Ying \\ Henan Mechanical and Electrical Vocational College, Xinzheng, Henan, China (wxkbbg@163.com)
}

\begin{abstract}
Chinese literature are marked with traditional culture. The Hongkong writer Huang Helang described his childhood hometown with the brushwork to reflect the national character and cultural, it reflects his high writing skills. He adopted the style "Focused on the love things to memory childhood, focused on the love people to recall homeland, paid high attention to the words, structures and grammar, the best structure suitable for the skillfully stitched". All that express the deeply longing and love of the hometown and motherland, so it was called the beauty prose.
\end{abstract}

Keywords - traditional culture, vision, nostalgia

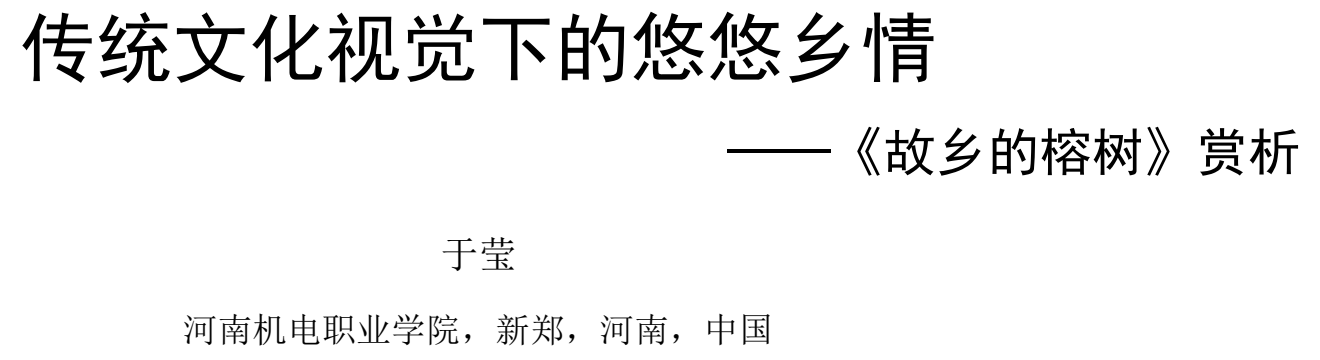

摘 要 中国文学无不打上传统文化的烙印, 香港作家黄河浪, 用一种反映民族特质文化的笔触写儿时的故乡, 体现了很高的写 作技巧。他采用 “寄情于物忆儿时, 寄情于人恋故土, 字煁句酌细雕刻, 佳构适宜巧缝合” 等方式, 抒发了对故乡、祖国深深的思念 与眷恋, 被人称为散文中的美文。

关键词 传统文化, 视觉, 乡情

\section{1. 引言}

传统文化在中国历史文明的长河中如涓涓细流、节节 侵润, 使人们的生活无不打上了她的烙印, 而反映社会生 活的文学作品, 更是与传统文化有着千丝万屡的联系, 传 统文化孕育了让人手不释卷的小说, 造就了激情洋溢的诗 歌, 积淀了感人泪下的戏剧, 也培育了无数丽句佳构的优 美散文。香港作家黄河浪, 用一种反映民族特质文化的笔 触写儿时的故乡, 他的故乡-一大榕树下, 乡里乡亲, 围 着榕树讲故事、求神灵、享生活, 和谐融洽, 其乐融融, 其质朴的乡情令人魂牵梦绕、肝肠寸断, 真是提故乡, 泪 汪汪, 写不完的往事, 述不尽的情思……

\section{2. 寄情于物忆儿时}

伟大诗人李白有: “会桃花之芳园, 序天伦之乐事” 之 说, 儒家文化中崇尚父子、兄弟融洽地聚在一起, 认为这 是生活的一大快乐。文章开端作者就带着传统文化的浓浓 韵味, 写 “我” 在都市生活之余偶遇闲㗇, 带着儿子逗着 小狗, 享着天伦之乐, 尽情玩要, 观摇曳的青翠, 享诱人 的清凉, 充满殹意, 其乐融融。似乎是一种自然的巧合, 住所的土坡上有两颗榕树, 看到它自然就想起了故乡的榕 树。仔细探究起来, 这是作者的精心构思, 匠心独运, 把 住所的榕树作为抒情的 “触发点”, 小儿子作为抒情的引子, 自然而然引出了对儿时趣事的回忆。引忆之人一一小儿子, 如同当年的我; 尤其又有了引忆之声一一哨笛, 作 者 “我” 小时候吹叶笛的情景, 就会再现眼前, 往事自然会让人浮 
想联翩, 不言而喻, 对小黑狗的描写是为了烘托哨音的美 妙和 “小儿子” 的乐态, 作者从选笛音为切入点, 开始了 回忆, 心像小鸟, 展翅飞去”, 把读者缓缓带入故乡, 溶 进故乡榕树下的美好生活。通过这些铺垫, 使乡思更为自 然, 使乡情更为浓郁, 也使读者不知不觉中随着作者, 感 受乡思的渴盼和乡情的真挚。榕树是南方司空见惯的树 木, 但枝繁叶茂叶子如化不开的团团绿云, 作者站在传统 文化的视觉下去欣赏它, 看着他就生出了情, 想到了迷蒙 的烟水、苍茫的群山, 为下文抒发的两种感情: 故乡情、 爱国情埋下伏笔。别林斯基说: “感情是诗情天性的最主要 的动力之一”, 作者把浓浓的乡情寄寓在对大榕树的描绘 里, 思绪如小鸟展翅飞翔, 使下文回忆儿时的故事顺理成 章: 笔下榕树驱干高大鬼斗悟, 长须䯽曲飘拂, 叶子像化不 开的团团绿云, 小溪流过榕树旁是清澈的, 溪水中的我鸟卵 石是彩色的, 鸭子在追逐欢笑, 石桥是洁白的, 石碑上是 刻着字的, 桥栏杆上小石狮子也被人摸光滑了......故乡的 夏天屋内如焚、土地冒烟, 而榕树像巨伞, 遮挡阴凉、荫 庇乡人。这些秀美的景、熟悉的物, 非常符合作者儿时的 心态; 逼真的画面, 如在眼前, 抒发了作者对故土的一草 一木的真挚的爱。作者就是这样把对故乡母亲的真情融入 到儿时的梦里, 而这些充满原野风味的特色文化, 都带着 作者的情, “我” 对故乡的情没有矫揉造作, 而是从字里行 间自然溢出。

\section{3. 寄情于人恋故土}

对故乡的思念是每一个游子潜藏于心底的一种思绪, 中国传统文化把乡愁分为三个方面: 一是对亲友、乡亲、 同胞的思念, 二是对故园旧时风景的怀念, 三是对历史文 化的滕恋。正如一位海外游子所说, 思想就是思念家乡的 味道、家乡的声音, 思乡的内容是丰富多彩的。文章紧紧 围绕 “我”, 选择故乡的人、故乡的事, 把对故乡的深情和 谐地揉合在一起。文章记述的都是作者亲身经历的往事、 趣事充满着生活气息, 他的抒情寄寓在对历史文化的眷恋、 对乡人的思念、同情与怀念上。文中所写人物很多, 但人 物形象不很突出, 往往是在抒情中人物转瞬即逝, 第一类 是在溪畔洗衣和汲水的少女, 在榕树上划船的小伙伴。这 类人物永远是那样纯真、活泼, 他们脑子里是种苗青青的 田野, 是燃烧着火红杜鹃的山坡和飘着芬芳小白花的橘树 林, 无忧无虑, 天真烂漫, 不知大人的辛苦。另一类人物 是身上无不带着旧时代的影子, 传统文化在他们身上有着 明显的折射的乡人, 他们迷信鬼神, 相信命运, 没有勇气 改变现状, 过着随遇而安的平静而艰辛生活的生活, 如讲 着故事的垂着长长胡子的最老最老的老人, 点着香烛、烧 着纸钱虔诚的祈求神灵的女人, 带着孩子在榕树上砍几刀
用汁液治皮癬的母亲, 蹑着三寸金莲唠唠叨叨嘱咐孩子小 心的祖母。他们都是如此的让人忘怀, 让人产生着浓烈的、 动情的、美丽的、清晰的感情, 使人觉得 “露从今夜白, 月是故乡明”, 同时也理解了古人的 “此夜曲中闻折柳, 何 人不起故国情” 的真正含义。

散文中的叙事非常简练, 作者的叙事也是为了写人、 抒情。如大蛇成精久藏在树洞中, 想要升天, 因伤害人畜, 激怒玉皇大帝, 神灵就利用闪电霹雾䢃开树干, 烧死蛇精; 每逢祭日老祖母都会叫我爬上榕树, 折几枝榕树枝, 插在 饭甑或蒸笼里祭祀祖先的神灵; 傍晚, 辛劳一天后人们, 躺在石板上, 讲三国、说水浒, 拉起胡琴, 用粗犷的喉咙 唱小曲, 在苦涩中寻短暂的安慰和满足。这些事让人想起 一句俗语 “老乡见老乡, 两眼泪汪汪”, 我们感觉作者写这 些内容时像在喝茶, 情思中有淡淡的苦涩, 又像在饮酒, 带着浓浓的辛辣, 思乡的眼泪有幸福也有苦涩, 作者在这 里表达的是对乡邻的深切同情与滕恋, 他的乡愁是浓缩了 的历史、浓缩了的故乡传统文化, 是充满人情味的。家乡 的概念在传统文化中是一个内涵丰富的概念, 作者在本文 中把故乡喻为母亲, 作者笔下的家乡是贫穷的, 乡亲是愚 昧的, 但 “狗不嫌家贫, 儿不嫌母丑”, 作者作为游子的爱 却愈发深情。中国宗教文化把母亲称之为生命的缔造者、 养育者、守护者, 家乡母亲无条件的给了游子美好的童年、 童真的伙伴、朴实的乡邻和说不完的故事, 作为游子应该 无私的回报, 而自己却远离家乡千里万里, 对母亲的愧疚 与思念, 凝成浓浓的乡愁, 在作者心头索绕, 生命有尽头, 思母无穷期, 作者把 “谁言寸草心, 报得三春晖” 寄寓在 榕树身上, 深情地写道 “故乡的亲切的榕树啊, 我是在你 绿阴的怀抱中长大的, 如果你有知觉, 会知道我在这遥远 的异乡怀念着你吗? ” 接着, 作者按照中国传统习俗中礼 尚往来的观念, 仍然把情寄寓榕树, 希望故乡母亲和自己 有心电感应、精神相通, 也会像慈母一样, 思念这飘泊天 涯的游子。

\section{4. 字㽎句酌细雕刻}

传统文化追求散文的字词美, 主张散文的字句都能体 现一种朴素、自然、流畅、简净等特点, 字词要散中见整, 清新自然, 不刻意雕饰而不乏文采, 不有意追求而自得其 意蕴。在古代散文中, 字句不是语言的外壳, 而是散文的 精髓, 负载着散文美的灵魂。本文的字句美体现在如下几 个方面: 一是色彩画面美, 作者把榕树在风中摇曳, 写作 “摇曳赏心悦目的青翠”; “注一潭诱人的清凉”, 清新、碧 绿、枝繁叶茂的榕树画面清晰可见, 同时也抒发了作者对 榕树的喜爱; 眼前的小黑狗摇动毛茸茸的尾巴、抬起乌溜 溜的眼睛, 更是一幅逼真画面, 映祄童趣; 嘎嘎嘎地追逐 
欢笑的成群的鸭子, 更是一幅美丽的自然画面。二是个别 字画龙点睛美, 一字千金, 无法替代, 如 “注一潭诱人的 清凉的 “注” 字表示阴凉是不间断的、无私的; “苍虬多筋 的树干” 中” 苍虬多筋” 极言榕树的历史悠久、饱经沧桑; 蹑着缠得很小的 “三寸金莲” 的 “蹑” 字活画出老奶奶走 路的姿态。三是语法修辞美, 运用比喻排比等修辞手法, 如写榕树的“叶子如片片碧玉, 在息裹的风中晃动如耳坠”, 形象生动的写出了榕树的叶子在风中婆娑起舞的美姿, 体 现散文的自然美; “两棵高大的榕树撑开遮天巨伞”, 写出 了榕树的古老与枝繁叶茂, 艺术传神, 映射出了故乡像大 榕树一样荫蔽着乡亲。四是句子的音乐抒情美, “那泪泪的 溪水流走了我童年的岁月, 那古老的石桥镌刻着我深深的 记忆, 秧苗青青的田野上, 绕过燃烧着火红杜鹃的山坡, 穿过飘着芬芳的小白花的橘树林”, “早上醒来, 清露润湿 了头发, 感到凉搜搜的寒意, 才发觉枕头不见了, 探头往 桥下一看, 原来是掉到溪里, 吸饱了水, 涨鼓鼓的, 搁浅 在乱石滩上……”读起来富有韵味, 简直像是在唱歌, 抒 发了作者对故乡的挚爱。五是句子的含蓄和谐美。“如水的 月华给山野披上一层透明的轻纱, 将一切都变得不很真实, 似梦境, 似仙境。在睡意中, 有嫦娥驾一片白云悄悄飞过, 有桂花的清香自榕树枝头轻轻酒下来。” “那世世代代讲不 完的传说吗? 但那像榕树一样垂着长长胡子的讲故事老人 已经去世了; 过年时常叫我攀折榕树枝叶的老祖母也已离 开人间许久了; 只有桥栏杆上的小石狮子, 还在听桥下的 溪水滔滔流淌吧? ”这些句子的抒情时淡时浓、时明时暗, 没有一句直接写对故乡的依恋, 但情思却胜过千言万语。

\section{5. 佳构适宜巧缝合}

散文在中国文学史上可谓历史悠久, 形成了固定的传 统模式, 黄河浪完全是在传统散文的格式影响下写本文的, 从《故乡的榕树》中可以找到许多诸子百家、唐宋八大家 散文的影子, 即是散文又是美文。正如刘妿思所说: “物以貌 求, 心以理应。”意思是仅写事物的表面现象是远远不够的, 作家心里必须产生情理来作为反映, 形成一定的行文思路, 才能写出好文章, 本文创作就是如此。文中叙述的是四十 年前的故乡, 时间跨度比较大, 但作者安排结构却非常自 然, 以榕树为人、事的 “连接点”, 围绕榕树描写了一系列 的故事: “树舟戏要”, “榕树传说”, “树下祭祀”, “纳凉消 夜”, 最后以榕树为乡情的 “凝聚点”, 把自己的绵绵情思 化作心灵的呼唤, 凝聚在苍老萮郁的榕树中。文章发于榕 树, 收于榕树, 首尾呼应, 浑然一体。

第一是开篇层层铺垫。文章开篇写 “住所附近的土坡 上, 有两棵苍老蓊郁的榕树, 以广阔的绿荫遮蔽着地
面。” 作者由眼前的榕树想到故乡的榕树, 由眼前景引出 故乡情, 榕树是作者思乡怀旧的联系物和纽带, 又是叙事 绘景的线索, 贯穿文章始终。第二是文章中间时时缝合, 文章主体部分是回忆故乡的景物、人和儿时的趣事, 过渡 句、过渡段的运用达到了炉火纯青的地步, 不时进行巧妙 地缝合。如开头由眼前过渡到回忆儿时用: “而我的心却像 一只小鸟, 从哨音里展翅飞出去, 飞过迷的烟水、苍茫的 群山, 停落在故乡熟悉的大榕树上。” 第四段结尾一句: “记 忆里的故事有榕树的叶子一样多.......”起到了联系上下文 的作用, 告诉读者接下去要写和榕树有关的故事了。倒数 第二段写完家乡的故事之后, 用 “那样的日子不会回来了”, 自然地过度到眼前, 开始了下面的集中抒发情思了。由于 作者时时注意过度、工于缝合, 使上下文材料紧密勾连, 思路承接自然贯通, 情感抒发得淋漓尽致, 收到了很好的 表达效果。第三, 结尾处处呼应。既照应开头, 又交代两 棵老榕树 “幸好另一棵安然无恙, 仍以它浓蔚的绿叶荫庇 着乡人。”还有对老奶奶的交代 “过年时常叱我攀折榕树枝 叶的老祖母也已离人间许久了。”对长着长长胡子老人的交 代 “那像榕树一样垂着长长胡子的讲故事老人已 经去世 了。”文章叙事抒情连为一体, 抒发了对故乡的深切怀念和 真挚眷恋之情。这些呼应做到了使文章结构更加完善, 抒 情更深沉、更浓郁。

\section{6. 结论}

作者黄河浪深受传统文化的濡养, 他的骨子里流淌的 是传统中国文化的血液, 热爱祖国、思念故土成了本文的 主旋律, 感人之深, 催人泪下, 他对故乡的滕恋带着儒家 的传统血脉, 他抒发的思乡情又散发着浓郁的泥土气息, 眼前、故乡、儿时、现代随意的起承转合, 榕树搭打起了 抒情的桥梁, 读后使人感受到了一种艺术的享受, 不失为 一篇优美的散文佳作。

\section{参考文献(References)}

[1] Liu Hui. A quality suggestive of poetry or painting words "homesickness -- design teaching home banyan". Popular Science (Science Education), 2013 (01): 12-18

[2] Gu Dayong. "Second life" prose "Hometown" ambiguous meaning. Chinese literature, 2013 (12): 56-58

[3] Chang Miao. Artistic features Zengqi hometown series of novels. Wenzhou Vocational and Technical College, 2013 (12) :43-44

[4] Xu Fengcai. Spiritual madrigal -- on Hu Changguo's prose. Zhongzhou Academic Journal, 2013 (12): 87-88 